\section{BMJ Paediatrics Open}

\title{
National survey of feasibility of NIV trials for management of children with bronchiolitis
}

Anna Rosala-Hallas (D , , ${ }^{1}$ Ashley P Jones (D) , ${ }^{1}$ Emma Bedson, ${ }^{1}$ Vanessa Compton, ${ }^{2}$ Ricardo M Fernandes, ${ }^{3,4}$ David Lacy, ${ }^{5}$ Mark D Lyttle, ${ }^{6,7}$ Matthew Peak, ${ }^{8}$ Kent Thorburn, ${ }^{2}$ Clare van Miert, ${ }^{2,9}$ Kerry Woolfall, ${ }^{10}$ Paul S McNamara ${ }^{11}$

ABSTRACT

Background Bronchiolitis is a major cause of admission to hospital in children. Non-invasive ventilation (NIV) support with continuous positive airway pressure (CPAP) or high-flow nasal cannula (HFNC) oxygen is routinely used for infants in the UK with bronchiolitis.

Objective To establish UK paediatric practice regarding management of bronchiolitis, and to explore issues pertinent to the design of a potential future randomised controlled trial of NIV.

Received 26 June 2020 Revised 7 August 2020 Accepted 25 August 2020

Check for updates

\section{(C) Author(s) (or their} employer(s)) 2020. Re-use permitted under CC BY-NC. No commercial re-use. See rights and permissions. Published by BMJ.

For numbered affiliations see end of article.

Correspondence to Dr Paul S McNamara; mcnamp@liverpool.ac.uk
Design Screening logs were completed in hospitals in England capturing information on paediatric bronchiolitis admissions. An online national survey of clinical practice was disseminated to healthcare professionals (HCPs) across the UK to ascertain current management strategies. Results Screening logs captured data on 393 infants from 8 hospitals. Reasons for admission were most commonly respiratory distress and/or poor fluid intake. Oxygen was administered for $54 \%$ of admissions. Respiratory (CPAP and HFNC) and non-respiratory support administered varied considerably. The national survey was completed by 111 HCPs from 76 hospitals. Data were obtained on criteria used to commence and wean NIV, responsibilities for altering NIV settings, minimum training requirements for staff managing a child on NIV, and numbers of trained staff. Most centres were interested in and capable of running a trial of NIV, even out of normal office hours.

Conclusions Respiratory and non-respiratory management of bronchiolitis in UK centres varies widely. A trial of HFNC oxygen therapy in this group of patients is feasible and HCPs would be willing to randomise patients into such a trial. Future work should focus on defining trial eligibility criteria.

\section{INTRODUCTION}

Bronchiolitis is a major cause of admission to hospital in children. ${ }^{12}$ Between 2004 and 2012, 8172 children under the age of 1 year were admitted to a paediatric intensive care unit (PICU) for bronchiolitis in England. ${ }^{3}$ From 2004 to 2011, the overall average PICU admission rate increased by $1.8 \%$ each year. ${ }^{3}$

Bronchiolitis management is centred on oxygen therapy for hypoxia, respiratory support and good hydration. Early use

\section{What is known about the subject?}

Bronchiolitis is one of the the most common causes of hospitalisation in infancy.

- Non-invasive ventilation and specifically high-flow nasal cannula oxygen therapy is increasingly used for children with bronchiolitis based on limited evidence in the UK.

- There is widespread support among paediatricians in the UK for a trial of non-invasive ventilation to guide UK practice.

\section{What this study adds?}

Respiratory and non-respiratory management of bronchiolitis in UK centres varies widely.

- A trial of high-flow nasal cannula oxygen therapy is feasible and healthcare professionals would be willing to randomise patients into such a trial.

of non-invasive ventilation (NIV), such as continuous positive airway pressure (CPAP) or heated humidified high-flow nasal (HFNC) oxygen $\left(\mathrm{O}_{2}\right)$, may have an impact on outcome by avoiding disease progression. ${ }^{4}$ There has been an increase in the use of HFNC in routine clinical practice for moderate-tosevere bronchiolitis; however, until recently, there has been little evidence to guide practice, and there have been no studies using NHS patients from the UK. ${ }^{5}$ Recently, a number of reports have raised concerns regarding its cost effectiveness in bronchiolitis. ${ }^{7}$

The objectives of this study were to assess current UK practice regarding bronchiolitis management in terms of the type of NIV methods used and the criteria for commencing and weaning NIV. We also wished to explore issues pertinent to the design of a potential future randomised controlled trial (RCT) of NIV. This study formed part of a larger research project (Non-Invasive Ventilation 
for the Management of Children with Bronchiolitis: a feasibility study (NOVEMBR)). ${ }^{8}$

\section{METHODS}

A point-prevalence study, using paper screening logs of paediatric hospital admissions with bronchiolitis, was prospectively completed, by research nurses from district general hospitals and paediatric tertiary centres hospitals across England. The logs gave guidelines for completion and captured: patient age, referral route, demographic and clinical risk factors, reasons for admission, treatment interventions during admission, method of $\mathrm{O}_{2}$ delivery and amount of $\mathrm{O}_{2}$ (if any), and length of hospital stay. In total, 14 hospitals were approached for participation of which eight responded (five district general hospitals and three paediatric hospitals; see online supplemental list 1 for a list of the hospitals). The logs were circulated in two waves: the first wave included five hospitals and ran from 12 December 2016 to 12 January 2017; the second wave included three different hospitals from 11 December 2017 to 13 January 2018. The same $\log$ was used for all hospitals; repeat sampling was not used. Data on all patients admitted with a diagnosis of bronchiolitis during these time periods to these hospitals were captured.

In addition, an online national survey (online supplemental material) was developed by the study management group to explore current practices of HCPs when managing bronchiolitis. The survey was piloted among clinical members of the Study Management Group, which comprised PICU, respiratory and general paediatricians, paediatric nurses and research nurses. Amendments made from the piloting process were improvements to the clarity and understanding of the survey by changes to some of the language. The survey was disseminated to lead paediatricians at all paediatric centres in the UK through the National Institute for Health Research Clinical Research Network (CRN) Coordinating Centre to Specialty Cluster Office for Children and Local CRNs, and through the General and Adolescent Paediatric Research Collaborative UK and Ireland. The lead paediatricians were asked to complete the survey themselves or to pass it on to whoever they considered most appropriate. It was conducted online between 29 September 2017 and 31 January 2018. Respondents were asked to report their job title and give information about their hospital including: the number of estimated paediatric bronchiolitis admissions, type of NIV interventions used and who administers them, criteria for initiating and weaning CPAP and HFNC, availability of local bronchiolitis care pathways and lastly, questions to determine the acceptability to HCPs of running a clinical trial. Completion of the survey was deemed consent to participate.

Data from both the screening logs and the online national survey were summarised using descriptive statistics. Where questions were missed or responses 'Not known', percentages were derived using denominators for those who gave an answer only.
Advice from the HRA was sought and it was confirmed that ethical approval was not required for the online survey. Approval was not required for the screening exercise as only anonymous data were collected.

Patient and Public Involvement (PPI) was not included forthis component of the NOVEMBR study since the aim was to ascertain currentpractice amongst HCPs.

\section{RESULTS}

\section{Screening logs}

Table 1 gives a summary of the screening data. Three hundred and ninety-three patients were screened at eight hospitals across England (online supplemental list 1). Data by hospital are presented in online supplemental table 1 . The greatest proportion $(139 / 357,39 \%)$ were admitted in the afternoon and early evening (14:00-20:00). Median age at admission was 14 weeks (IQR: 8-29) and median length of hospital stay was 2 days (IQR: 1-3). Most referrals were via emergency departments $(246 / 391,63 \%)$ or from general practitioners $(99 / 391,25 \%)$. It was possible for multiple reasons for admission to be selected for each patient; among the most frequent, over half (203/392, $52 \%$ ) reported difficulty with breast feeding/inadequate oral fluid intake, $36 \%(142 / 392)$ other respiratory problems, including cough and increased work of breathing, $31 \%(121 / 392)$ severe respiratory distress and 27\% (106/392) of children looked seriously unwell to a HCP. Commonly reported risk factors for hospital admission included age less than 3 months $(165 / 357,46 \%)$ and/ or prematurity $(89 / 357,25 \%) ; 34 \%$ (120/357) reported no risk factors. Non-respiratory interventions included: nasogastric fluids $(157 / 354,44 \%)$, antibiotics $(87 / 354$, $25 \%)$, nebulised treatments $(52 / 354,15 \%)$ and intravenous fluids $(37 / 354,10 \%) ; 38 \%(134 / 354)$ reported no treatment intervention. There was considerable variation across hospitals: nasogastric fluids use ranged from $17 \%$ to $77 \%$ of infants, antibiotics from $9 \%$ to $67 \%$, nebulisers from $7 \%$ to $55 \%$ and intravenous fluids from $1 \%$ to $37 \%$ (figure 1). Oxygen was delivered to 191 (54\%) patients. Multiple methods for $\mathrm{O}_{2}$ delivery could be selected; methods reported were low-flow nasal cannula $(103 / 191,54 \%)$, rebreathe mask $(42 / 191,22 \%)$, head box with humidified $\mathrm{O}_{2}(25 / 191,13 \%)$, HFNC (52/191, $27 \%)$, CPAP $(18 / 191,9 \%)$ and intubation and ventilation $(21 / 191,11 \%)$.

\section{National online survey of current practice}

The survey was accessed by 123 individuals. Twelve (9\%) completed demographic details only and were excluded from the summaries; the remaining $111(91 \%)$ responders were from 76 hospitals (online supplemental list 2). The majority $(83 / 111,75 \%)$ of respondents were from district general hospitals; 25\% (28/111) were from paediatric tertiary centres. According to the Royal College of Paediatrics and Child Health workforce document published in 2019, there are 189 paediatric centres with inpatient facilities in the UK of which 35 are considered specialist 


\begin{tabular}{|c|c|}
\hline & N (\%) \\
\hline \multicolumn{2}{|l|}{ Patient age (weeks) } \\
\hline $\mathrm{N}$ & 378 \\
\hline Mean (SD) & $20.0(15.9)$ \\
\hline Median (IQR) & $14.2(7.5-29.1)$ \\
\hline Min, Max & $1.3-82.4$ \\
\hline Missing & 15 \\
\hline \multicolumn{2}{|c|}{ Length of stay in hospital (days) } \\
\hline $\mathrm{N}$ & 390 \\
\hline Mean (SD) & $2.7(3.0)$ \\
\hline Median (IQR) & $2(1.3)$ \\
\hline Min, max & $0-24$ \\
\hline Missing & 3 \\
\hline \multicolumn{2}{|l|}{ Time of presentation } \\
\hline $\mathrm{N}$ & 357 \\
\hline 02:00-08:00 & $36(10 \%)$ \\
\hline 08:00-14:00 & $81(23 \%)$ \\
\hline 14:00-20:00 & $139(39 \%)$ \\
\hline 20:00-02:00 & $101(28 \%)$ \\
\hline Missing & 36 \\
\hline \multicolumn{2}{|l|}{ Referral route } \\
\hline $\mathrm{N}$ & 391 \\
\hline Accident and emergency & $246(63 \%)$ \\
\hline District general hospital & $16(4 \%)$ \\
\hline General practitioner & $99(25 \%)$ \\
\hline Open access & $17(4 \%)$ \\
\hline Other hospital & $10(3 \%)$ \\
\hline Readmission & $1(0.3 \%)$ \\
\hline Walk-in & $2(0.5 \%)$ \\
\hline Not known & 2 \\
\hline
\end{tabular}

\section{Risk factors*}

\begin{tabular}{|ll}
\hline N & 357 \\
\hline Baby born prematurely & $89(25 \%)$ \\
\hline Congenital heart defect & $7(2 \%)$ \\
\hline Neuromuscular disease & $1(<1 \%)$ \\
\hline Immunodeficiency disorders & $2(1 \%)$ \\
\hline Chronic lung disease & $8(2 \%)$ \\
\hline Young age ( $\leq 3$ months) & $165(46 \%)$ \\
\hline Other & $24(7 \%)$ \\
\hline No risk factors & $120(34 \%)$ \\
\hline Not known & 1 \\
\hline Missing & 35 \\
Reason for admission* & \\
\hline N & 392 \\
\hline Apnoea (reported or observed) & $21(5 \%)$ \\
Child looks seriously unwell to a HCP & $106(27 \%)$ \\
\hline &
\end{tabular}

\begin{tabular}{ll}
\hline Table 1 Continued & N (\%) \\
\hline $\begin{array}{l}\text { Severe respiratory distress } \\
\text { Central cyanosis }\end{array}$ & $121(31 \%)$ \\
$\begin{array}{l}\text { Persistent } \mathrm{O}_{2} \text { saturation }<92 \% \text { when } \\
\text { breathing air }\end{array}$ & $30(8 \%)$ \\
$\begin{array}{l}\text { Difficulty with breast feeding/ } \\
\text { inadequate oral fluid intake }\end{array}$ & $203(52 \%)$ \\
\hline Social circumstances & $2(1 \%)$ \\
\hline $\begin{array}{l}\text { Other respiratory } \\
\text { Other }\end{array}$ & $142(36 \%)$ \\
\hline Missing & $50(13 \%)$ \\
Method ${ }^{*}$ of $\mathrm{O}_{2}$ delivery & 1 \\
\hline $\mathrm{N}$ & 191 \\
\hline Nasal Cannula & $103(54 \%)$ \\
\hline Headbox with humidified $\mathrm{O}_{2}$ & $25(13 \%)$ \\
\hline Heated humidified high-flow nasal $\mathrm{O}_{2}$ & $52(27 \%)$ \\
\hline Rebreathe mask & $42(22 \%)$ \\
\hline CPAP & $18(9 \%)$ \\
\hline Intubation and ventilation & $21(11 \%)$ \\
\hline Other & $13(7 \%)$ \\
\hline No $\mathrm{O}_{2}$ used & 162 \\
\hline Not known & 3 \\
\hline Missing & 37 \\
\hline
\end{tabular}

*Multiple responses could be selected.

CPAP, continuous positive airway pressure; HCP, healthcare professional.

(tertiary) centres. ${ }^{9}$ Respondents were either consultants $(92 / 109,84 \%)$ or nurses $(12 / 109,11 \%$, table 2$)$.

Almost half $(47 \%, 38 / 81)$ of respondents stated that the estimated annual number of paediatric bronchiolitis admissions to their hospital with a length of stay of at least 1 day, was between 101 and 200, and 30\% (24/81) estimated between 51 and 100 . The majority $(71 / 84,85 \%)$ of respondents stated local bronchiolitis care pathways and/or guidance were available to them; $86 \%(75 / 87)$ reported the criteria for starting $\mathrm{O}_{2}$ was $\mathrm{SpO}_{2}<92 \%$. Six respondents $(6 / 88,7 \%)$, from separate hospitals, reported the ability to send home children with bronchiolitis on $\mathrm{O}_{2}$.

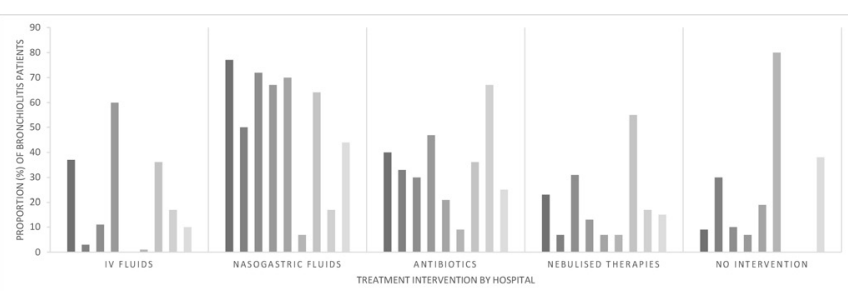

Figure 1 Screening responses - treatment interventions across hospitals. 
Table 2 Survey participant/hospital demographics

Number of respondents

Participant and hospital demographics (\%)

\begin{tabular}{lc}
\hline Job title/role & \\
$\mathrm{N}$ & 109 \\
Consultant & $92(84 \%)$ \\
\hline Nurse & $12(11 \%)$ \\
Other & $5(5 \%)$ \\
Missing & 2 \\
\hline
\end{tabular}

Number of children with bronchiolitis admitted to hospital (with $\geq 1$ day length of stay) per year

$\begin{array}{lc}\mathrm{N} & 81 \\ <50 & 5(6 \%) \\ 51-100 & 24(30 \%) \\ 101-200 & 38(47 \%) \\ 201-300 & 9(11 \%) \\ 301-400 & 2(2 \%) \\ >401 & 3(4 \%) \\ \text { Not known } & 28 \\ \text { Missing } & 2\end{array}$

Local bronchiolitis care pathways and/or guidance available

\begin{tabular}{ll}
$\mathrm{N}$ & 84 \\
Yes & $71(85 \%)$ \\
\hline No & $13(15 \%)$ \\
\hline Not known & 6 \\
\hline Missing & 21 \\
Criteria for starting $\mathrm{O}_{2}$ & \\
$\mathrm{~N}$ & 87 \\
$\mathrm{SpO}_{2}<92 \%$ & $75(86 \%)$ \\
Other & $12(14 \%)$ \\
Not known & 2 \\
\hline Missing & 22 \\
\hline
\end{tabular}

Do you send otherwise well children with bronchiolitis who are improving, home on $\mathrm{O}_{2}$ ?

$\mathrm{N} \quad 88$

\begin{tabular}{lc} 
Yes & $6(7 \%)$ \\
\hline No & $82(93 \%)$ \\
\hline Not known & 3 \\
\hline Missing & 20 \\
\hline
\end{tabular}

Methods to deliver $\mathrm{O}_{2}$ : therapy on the general medical practice ward*

\begin{tabular}{ll}
$\mathrm{N}$ & 86 \\
Nasal cannula & $84(98 \%)$ \\
Heated humidified high-flow nasal $\mathrm{O}_{2}$ & $73(85 \%)$ \\
Rebreathe mask & $50(58 \%)$ \\
Non-invasive CPAP & $49(57 \%)$ \\
Headbox with humidified $\mathrm{O}_{2}$ & $29(34 \%)$ \\
\hline
\end{tabular}

Table 2 Continued

\begin{tabular}{ll} 
Participant and hospital demographics & (\%) \\
\hline $\begin{array}{l}\text { Missing } \\
\text { Methods to deliver } \mathrm{O}_{2} \text { : therapy on the High } \\
\text { Dependency Unit* }\end{array}$ & 25 \\
$\mathrm{~N}$ & 73 \\
Heated humidified high-flow nasal $\mathrm{O}_{2}$ & $70(96 \%)$ \\
Non-invasive CPAP & $64(88 \%)$ \\
Nasal cannula & $56(77 \%)$ \\
Rebreathe mask & $39(53 \%)$ \\
Headbox with humidified $\mathrm{O}_{2}$ & $19(26 \%)$ \\
Missing & 38
\end{tabular}

*Multiple responses could be select.

CPAP, continuous positive airway pressure.

\section{CPAP/HFNC}

More respondents reported being able to deliver $\mathrm{O}_{2}$ on paediatric wards by HFNC $(73 / 86,85 \%)$ than CPAP $(49 / 86,57 \%) ; 55 \%$ reported the ability to deliver $\mathrm{O}_{2}$ using both treatment modalities. On High Dependency Units (HDU), the ability to deliver $\mathrm{O}_{2}$ using either was similar (HFNC, 70/73, 96\%; CPAP, 64/73, 88\%).

The modal estimate of infants with bronchiolitis that did not require $\mathrm{O}_{2}$ on admission reported by respondents was $11 \%-20 \%$, whereas the estimate of infants that did require $\mathrm{O}_{2}$ was $61 \%-70 \%$. Although the modal estimate of infants treated with CPAP or HFNC was similar $(0 \%-10 \%)$, the variation was more marked for HFNC, with some respondents estimating that up to $80 \%$ of patients requiring NIV in their centres would be treated with HFNC, compared with a maximum of $40 \%$ estimated to be treated with CPAP (online supplemental table 5).

Apnoea, type 2 respiratory failure, exhaustion and the child not improving on alternate therapies (mostly HFNC) were more commonly cited as criteria to start CPAP compared with HFNC (figure 2, online

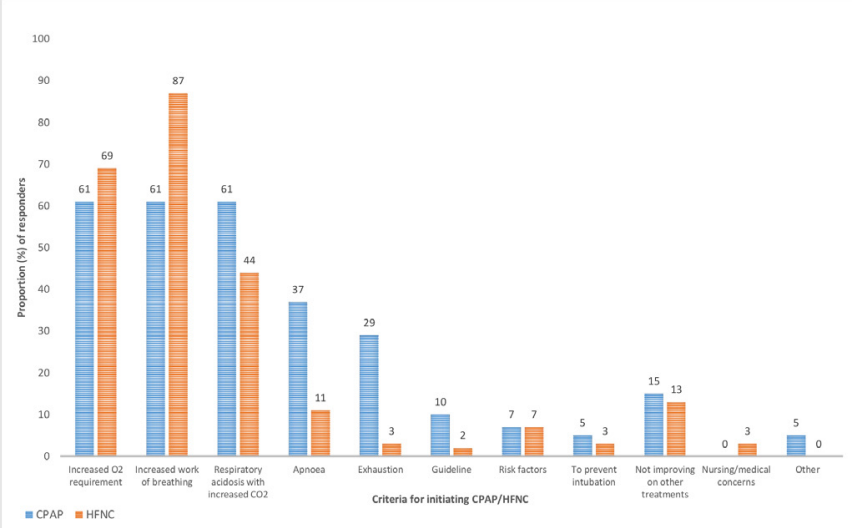

Figure 2 Survey responses - criteria for initiating continuous positive airway pressure (CPAP) compared to high-flow nasal cannula (HFNC). 
supplemental table 3); HFNC was started for increased work of breathing more often than CPAP. Correspondingly, resolved apnoea, and improved C02/respiratory acidosis were more commonly cited as criteria for weaning CPAP compared with HFNC. Responsibilities for altering CPAP/HFNC settings lay predominantly with the nursing staff, who were responsible in $40 \%(23 / 57)$ of cases on CPAP compared with $77 \%(46 / 60)$ of cases on HFNC. Minimum training requirements for staff to manage a child on CPAP/HFNC were similar for both methods and included: annual attendance of in-house training packages with and without clinical competency assessments, attendance to ad hoc training sessions run by equipment manufacturers and high dependency courses.

\section{Acceptability of a trial}

Most respondents $(34 / 41,83 \%)$ reported that it would be possible to run a clinical trial evaluating NIV treatment approaches in bronchiolitis even out-of-hours at their hospitals (online supplemental table 4). Forty respondents suggested at least one barrier to undertaking such a trial. Barriers included: current medical/nursing staff workload (15/40,38\%), availability of equipment ( $7 / 40$, $18 \%)$, lack of research nurse support $(4 / 40,10 \%)$ and lack of adequately trained staff to undertake a trial (3/40, $8 \%$ ). Correspondingly, 47 respondents suggested at least one enabler to undertaking a trial: having adequate medical, nursing and research nurse support (24/47, $51 \%)$, good training and education about any trial $(8 / 47$, $17 \%$ ) and importantly, having access to extra equipment $(8 / 47,17 \%)$. Sixty per cent $(47 / 78)$ estimated that $1-5$ HDU beds would be available in winter.

Respondents at $72 \%$ of sites reported always having one or more GCP trained doctor on every shift. Similarly, respondents at $45 \%$ of sites reported that their site had one or more GCP trained nurse on every shift.

\section{DISCUSSION}

In this prospective observational study of bronchiolitis admissions, large numbers of children (particularly young infants approximately 3 months of age) were hospitalised with this condition but generally for only a few days. Many (46\%) did not require oxygen during their admission, but in those who did, the method by which it was administered varied widely; this was particularly so for those requiring NIV. Despite publication of The National Institute for Health and Care Excellence (NICE) guidelines on bronchiolitis in 2015, ${ }^{3}$ there remains considerable variation in other aspects of management.

This study provided the opportunity to compare survey responses from a large number of UK paediatric HCPs with screening log data on actual bronchiolitis admissions to secondary and tertiary centres. Survey responses overestimated the proportion of children requiring $\mathrm{O}_{2}$ on admission compared with screening log data, and although modal estimates of CPAP usage were broadly in line with actual usage, estimates of HFNC usage underestimated actual usage. In interpreting these results, it should be acknowledged that the screening log data were based on admissions to only eight paediatric centres, and that there was a wide range of estimates of percentages of children treated with $\mathrm{O}_{2}$ and with NIV (particularly HFNC). It may also be the case that the screening results differ between district general hospitals and paediatric tertiary centres; however, our sample size did not permit such a comparison.

We compared reasons for starting and weaning NIV. Apnoea, type 2 respiratory failure, exhaustion and the child not improving on alternate therapies (mostly HFNC) were more commonly cited as criteria to start CPAP. Correspondingly, resolved apnoea, and improved $\mathrm{CO}_{2}$ /respiratory acidosis were more commonly cited as weaning criteria for CPAP than HFNC. The overall consistency of approach to starting and weaning NIV suggests the need for a consensus-based clinically pragmatic protocol for any future trial, and that agreeing criteria and a protocol to initiate and wean NIV across sites in a future trial is feasible. Furthermore, such criteria have already been adopted for a UK-based pragmatic trial in critically ill children on both stepping up and stepping down non-invasive respiratory support. ${ }^{10}$

Based on our findings, we would question whether it is currently feasible for a HFNC versus CPAP trial to be undertaken outside of PICUs and high-dependency units in the UK. This is primarily for reasons of capacity/capability, with many centres unable to support the use of CPAP on general paediatric wards and also given the recent funding and start of the FIRST-ABC (First-line support for Assistance in Breathing in Children) trial which is examining the non-inferiority of HFNC compared with CPAP ${ }^{10}$ However, a trial to assess the clinical effectiveness of HFNC versus standard oxygen therapy ('standard' agreed a priori) is feasible and one which many general paediatricians would likely support. A key issue for any such trial would be eligibility criteria. NOVEMBR and recently published RCTs of NIV for bronchiolitis suggest that eligibility cannot be based solely on the need for oxygen. ${ }^{5}$ We have shown here that although over half children hospitalised with bronchiolitis are hypoxic on admission, most do not require $\mathrm{O}_{2}$ for long (under 24 hours), do not deteriorate that frequently, and do not have prolonged inpatient admissions. Even for those hypoxic children at high risk of severe bronchiolitis (ie, those less than 3 months of age or born prematurely), the median (IQR) length of stay in hospital was only 2 (1-3) days. Key eligibility criteria for any future trial will likely have to include both need for $\mathrm{O}_{2}$ and increased work of breathing, and take into account risk factors such as young age/prematurity. It is these infants for whom HFNC likely has the biggest potential to demonstrate clinical and cost effectiveness. A retrospective cohort study published in 2018 identified predictors of escalated care in bronchiolitis and used these to derive a risk score to outline higher risk patients; validation of such a score would be beneficial. ${ }^{11}$ 
The screening logs highlighted a large variation in the frequency with which various non-respiratory interventions were used in children with bronchiolitis. Variation on this scale has previously been reported between countries, but not to our knowledge within the UK. ${ }^{12}$ When designing potentially large multicentre trials of NIV for children with bronchiolitis, an appreciation of this sort of variation in practice may be needed when planning patient recruitment per site and trial acceptability.

There were two limitations of note, the first being that in the survey multiple responses from the same hospital could have inflated the proportions for certain responses. To check the validity of our results, we looked at the results with each hospital included only once for each response level (online supplemental tables 2-4) and found that the proportions were similar. The second limitation was that participants from the same hospital occasionally reported different answers, which is likely due to different perspectives depending on the job roles of the respondents; however, sample sizes prevented us from exploring differences between HCP subgroups (ie, nurses from general paediatric wards and those from HDU).

We have established that there is a wide variety of practice across the UK in the respiratory and non-respiratory treatments given to infants with bronchiolitis. Our results also suggest that a trial of NIV is feasible and that HCPs would be willing to randomise patients into an NIV trial. Future work should now focus on defining the eligibility criteria for such a trial.

\footnotetext{
Author affiliations

${ }^{1}$ Liverpool Clinical Trials Centre, Department of Biostatistics, University of Liverpool (a member of Liverpool Health Partners), Liverpool, UK

${ }^{2}$ Paediatric Intensive Care Unit, Alder Hey Children's NHS Foundation Trust, Liverpool, UK

${ }^{3}$ Instituto de Medicina Molecular, Clinical Pharmacology and Therapeutics, Faculty of Medicine, Universidade de Lisboa, Lisbon, Portugal

${ }^{4}$ Department of Paediatrics, Lisbon Academic Medical Centre, Hospital de Santa

Maria, Lisbon, Portugal

${ }^{5}$ Department of Paediatrics, Wirral University Teaching Hospital NHS Foundation Trust, Wirral, UK

${ }^{6}$ Emergency Department, Bristol Royal Hospital for Children, Bristol, UK

${ }^{7}$ Faculty of Health and Applied Sciences, University of the West of England, Bristol, UK

${ }^{8}$ Clinical Research Division, Alder Hey Children's NHS Foundation Trust, Liverpool, UK

${ }^{9}$ School of Nursing and Allied Health, Liverpool John Moores University, Liverpool, UK

${ }^{10}$ Institute of Population Health and Society, University of Liverpool, Liverpool, UK

${ }^{11}$ Institute of Child Health, University of Liverpool, Liverpool, UK
}

Acknowledgements The authors would like to acknowledge the healthcare professionals who participated in the screening log and survey of national practice. They also would like to thank the funder, the NIHR Research for Patient Benefit Programme.

Contributors CvM and PM conceived the study. CvM, PM, RF and KW designed the study. EB, MP, KT, VC and DL were members of the study management group. AR-H analysed the data. AJ supervised data analysis. AR-H, APJ and PM drafted the manuscript. All authors reviewed and provided comments on the manuscript.
Funding This research was funded by the National Institute for Health Research (NIHR), Research for Patient Benefit (RfPB) Programme (Grant Reference Number PB-PG-1014-35081).

Disclaimer Views expressed are those of the authors and not necessarily those of the NHS, the NIHR or the Department of Health.

Competing interests CvM was an invited speaker at a meeting sponsored by Fisher \& Paykel. PM sits on an independent data monitoring and safety committee of an early phase trial of an antiviral treatment for bronchiolitis funded by Pulmocide and as an advisor for antiviral trials for bronchiolitis funded by Janssen and Alios. RF has served on independent data monitoring and safety committees of early phase trials in bronchiolitis funded by Ablynx and on a clinical endpoint committee for an RSV vaccine trial funded by Janssen.

Patient consent for publication Not required.

Provenance and peer review Not commissioned; externally peer reviewed.

Data availability statement Data are available upon reasonable request. The datasets generated are available from the corresponding author on reasonable request.

Supplemental material This content has been supplied by the author(s). It has not been vetted by BMJ Publishing Group Limited (BMJ) and may not have been peer-reviewed. Any opinions or recommendations discussed are solely those of the author(s) and are not endorsed by BMJ. BMJ disclaims all liability and responsibility arising from any reliance placed on the content. Where the content includes any translated material, BMJ does not warrant the accuracy and reliability of the translations (including but not limited to local regulations, clinical guidelines, terminology, drug names and drug dosages), and is not responsible for any error and/or omissions arising from translation and adaptation or otherwise.

Open access This is an open access article distributed in accordance with the Creative Commons Attribution Non Commercial (CC BY-NC 4.0) license, which permits others to distribute, remix, adapt, build upon this work non-commercially, and license their derivative works on different terms, provided the original work is properly cited, appropriate credit is given, any changes made indicated, and the use is non-commercial. See: http://creativecommons.org/licenses/by-nc/4.0/.

\section{ORCID iDs}

Anna Rosala-Hallas http://orcid.org/0000-0001-8012-9995

Ashley P Jones http://orcid.org/0000-0001-5253-730X

\section{REFERENCES}

1 Florin TA, Plint AC, Zorc JJ. Viral bronchiolitis. Lancet 2017;389:211-24.

2 Reeves RM, Hardelid P, Gilbert R, et al. Estimating the burden of respiratory syncytial virus (RSV) on respiratory hospital admissions in children less than five years of age in England, 2007-2012. Influenza Other Respi Viruses 2017;11:122-9.

3 Green CA, Yeates D, Goldacre A, et al. Admission to hospital for bronchiolitis in England: trends over five decades, geographical variation and association with perinatal characteristics and subsequent asthma. Arch Dis Child 2016;101:140-6.

4 Nice bronchiolitis guideline, 2016. Available: https://www.nice.org. uk/guidance/ng9 [Accessed Feb 2020].

5 Franklin D, Babl FE, Schlapbach LJ, et al. A randomized trial of high-flow oxygen therapy in infants with bronchiolitis. N Engl J Med Overseas Ed 2018;378:1121-31.

6 Kepreotes E, Whitehead B, Attia J, et al. High-Flow warm humidified oxygen versus standard low-flow nasal cannula oxygen for moderate bronchiolitis (HFWHO RCT): an open, phase 4, randomised controlled trial. Lancet 2017;389:930-9.

7 Ralston SL. High-Flow nasal cannula therapy for pediatric patients with bronchiolitis: time to put the horse back in the barn. JAMA Pediatr 2020;174:635-6.

8 van Miert C, Fernandes RM, Eccleson $\mathrm{H}$, et al. Non-invasive ventilation for the management of children with bronchiolitis (NOVEMBR): a feasibility study and core outcome set development protocol. Trials 2018;19:627

9 Royal College of paediatrics and child health. workforce census: UK overview report, 2019. Available: https://www.rcpch.ac.uk/ resources/workforce-census-uk-overview-report-2019 [Accessed July 2020].

10 NIHR research award. FIRST-ABC. Available: https://fundingawards. nihr.ac.uk/award/17/94/28 [Accessed Feb 2020].

11 Freire G, Kuppermann N, Zemek R, et al. Predicting Escalated care in infants with bronchiolitis. Pediatrics 2018;142:e20174253. 
12 Schuh S, Babl FE, Dalziel SR, et al. Practice variation in acute Pediatrics 2017;140:e20170842. bronchiolitis: a pediatric emergency research networks study. 